\title{
Stammbucheinträge:
}

\section{Friedrich Hölderlin}

"Noch viel Verdienst ist übrig, auf! hab es nur! Die Welt wird's ken[n]en."

(aus: Friedrich Klopstock „Der Rheinwein“)

Dies von Deinem Hölderlin

Nürtingen, d. 1. oct. 1786

\section{Maria Eleonora Heinrica Hölderlin (Hölderlins Schwester)}

„Nie schenkt der Stand, nie schenken Güter Dem Menschen die Zufriedenheit

Die wahre Reihe der Gemüther Ist Tugend und Genügsamkeit" (aus: Christian Fürchtegott Gellert: "Zufriedenheit mit seinem Zustande", 3. Strophe)

Hiermit empfiehlt sich dem H[errn] Besitzer

Zum geeinigten Gedenken

Ihre ergebenste Freundin

M.E.H. Hölderlin

Nürtingen, d. 2. oct. 1786

\section{Johanna Christiana Gok (Hölderlins Mutter)}

„Freund! mache dich verdient um anderer Wohlergehen. Denn was ist göttlicher, als wenn du liebreich bist; und mit Vergnügen eilst, dem Nächsten beizustehen, der, wenn er Großmuth sieht, großmüthig dankbar ist."

laus: Christian Fürchtegott Gellert "Der arme Schiffer", Werke, Bd. 1, Frankfurt a. Main 1979, S. 91f.)

Zum freundschaftlichen Angedenken beigesetzt von Ihrer ergebenen Dienerin,

J.C.G. N. d. 1. oct. 1786

\section{Bedeutende Neuerwerbungen}

\section{Hermann der Cherusker und Friedrich I. gegen Karl V.: Eine Flugschrift des Reutlingers Johann}

\section{Schradin aus der Zeit des Schmalkaldischen Krieges}

Schradin, Johannes: Warhaffte [...] erzelung der bösen anschleg vnnd practica, so wider die löbliche protestirende stende [...], durch gottes vnd seiner Kirchen feinde, den papst und seinen Anhang [...] fürgenomen vnnd ertacht seind. [...]

Deutsche Handschrift, Papier, 16. Jh.

Umfang: 12 Blätter

Neuerer Halbpergamenteinband, mit Marmorbuntpapier bezogen
Im Juli des Jahres 1546 - der Schmalkaldische Krieg zwischen Katholiken und Protestanten ist gerade ausgebrochen oder zumindest zum Greifen nahe - publiziert der Reutlinger Theologe Johannes Schradin eine Flugschrift, die auf ungewöhnliche und originelle Weise die evangelischen Stände zum Kampf gegen den katholischen Kaiser Karl V. aufruft: Einem Protestanten, der sich angesichts der unruhigen Zeiten über das Schicksal seines Landes sorgt, begegnen im Traum Gestalten aus unterschiedlichen Epochen der 'deutschen' Geschichte. Neben Arminius (Hermann dem Cherusker), Ariovist und Friedrich I. Barbarossa gehört 
auch der damals noch nicht lange verstorbene Landsknechtführer Georg von Frundsberg zu diesem Quartett. Die vier Herren - selbst Regenten bzw. Heerführer - sichern dem Ratsuchenden ihre volle moralische Unterstützung zu. Unter Rückgriff auf ihre persönlichen Erfahrungen setzen sie ihm auseinander, weshalb es legitim sei, sich Karl V. mit Waffengewalt zu widersetzen.

Der gereimte Kriegsaufruf reagiert somit auf die Bedenken einer reformierten Bürgerschaft, sich mit Waffen gegen die Obrigkeit zu wenden. Er umfasst etwa 600 Knittelverse und wurde in mehreren Drucken verbreitet. Es sind Ausgaben aus dem Jahr 1546 bekannt, die in Wittenberg, Magdeburg und Erfurt, aber auch im süddeutschen Raum (UIm und möglicherweise Tübingen) gedruckt wurden. Seine Identität gibt der Autor nicht ohne weiteres preis: Lediglich seine Initialen sind am Schluss der Drucke genannt. Zudem verbirgt sich jedoch der vollständige Name in einem Akrostichon: Die Anfangsbuchstaben der letzten 29 Verse, die einen gebetsartigen Abschluss beinhalten, ergeben untereinandergelesen die Worte "Johannes Schradin von Reutlingen".

Die Zurückhaltung bei der Namensnennung war durchaus berechtigt: Nach dem Sieg der kaiserlichen Truppen floh Johannes Schradin für mehrere Jahre aus seiner Heimatstadt, da er die Verfolgung durch die Kaiserlichen fürchten musste - war doch in einer weiteren Schrift, in der er ebenfalls zum Kampf gegen Karl V. aufruft, sein Name explizit genannt.

Die auf der Stuttgarter Antiquariatsmesse im Januar 2012 erstandene handschriftliche Wiedergabe des Textes birgt einige Rätsel: Woher kommt sie? Wo wurde sie bislang aufbewahrt? Der in neuerer Zeit entstandene Einband weist keine Provenienz- hinweise auf, auch in der Handschrift selbst sind Spuren früherer Besitzer nicht zu finden.

Vor allem aber stellt sich die Frage, von wem das Manuskript geschrieben wurde - und zu welchem Zweck. Die Flugschrift wurde 1546 im Druck verbreitet; sollte es sich hier vielleicht um eine Vorlage für die Drucklegung handeln, möglicherweise gar von der Hand des Autors selbst - und somit um ein Autograph Schradins?

Gegen diese These sprechen mehrere Umstände, von denen ich hier zwei nennen möchte. Zunächst deuten die Wasserzeichen des beschriebenen Papiers nach einer ersten oberflächlichen Untersuchung auf eine Entstehungszeit um 1570 hin. Da Schradin um 1560 starb, kann es sich auch nicht um eine spätere, redigierte Fassung von eigener Hand handeln. Zudem weist die Handschrift signifikante Abweichungen zu den von mir bislang zum Vergleich herangezogenen Druckausgaben auf. Besonders augenfällig sind die - wohl zumeist stilistisch motivierten - Eingriffe am Schluss des Textes: Dadurch, dass der Schreiber einige Worte umstellt oder durch andere Begriffe ersetzt, ändert sich ein Teil der Anfangsbuchstaben der letzten 29 Zeilen. Das Akrostichon, das sich in diesen Zeilen verbirgt, wurde also vom Abschreiber nicht als solches erkannt. Es dürfte sich somit um die in einigem räumlichen und zeitlichen Abstand entstandene Abschrift und Modifizierung eines der 1546 veröffentlichten Drucke handeln, möglicherweise für den privaten Gebrauch, möglicherweise auch als Vorlage für einen geplanten Neudruck.

Viele Fragen zu den Entstehungsumständen und zur Geschichte des Büchleins bleiben offen - und damit bietet diese Neuerwerbung beste Voraussetzungen, an ihr und über sie zu forschen. 